\title{
O PLANEJAMENTO DE ENSINO EDUCACIONAL COMO ESTRATÉGIA DE MUDANÇA DA EDUCAÇÃO ESCOLAR
}

Ivete Brito e BRITO ${ }^{1}$

Escola de Aplicação da Universidade Federal do Pará - UFPA

britoivete15@gmail.com

Resumo: $O$ presente texto, a partir de reflexões preliminares, objetiva evidenciar a importância do Planejamento de ensino educacional nos seus diferentes niveis, e caracterizar as diferentes concepções (Tendências Pedagógicas-Filosóficas do Planejamento de ensino na construção coletiva da mudança da educação escolar, e como assumem papeis estratégicos em tais mudanças. As reflexões partem de estudos bibliográficos que permitem a discussão sobre os discursos construídos sobre planejamento de ensino escolar em diferentes tempos e espaços. Como objetivo de alcance maior foi possivel evidenciar a importância das novas tendências do planejamento de ensino escolar para a constituição de subjetividades com visões políticas em espaços de disputas e lutas culturais.

Palavras-Chave: Planejamento de ensino educacional; discursos; Mudança Escolar.

\begin{abstract}
The present text, based on preliminar reflections, aims to highlight the importance of teaching educational planning in its different levels, and characterize the different conceptions (pedagogical-philosophical trends of teaching planning in the collective construction of schooling change, and how they assume strategic roles in such changes. The reflections are based on bibliographic studies that allow the discussion of discourses constructed on school education planning in different times and spaces. As the goal of greater reach it was possible to highlight the inportance of the new tendencies of the school education planning for the construction of subjectives with political views in cultural discussions and struggles fields.
\end{abstract}

Key-words: Teaching Educational Planning; Discourses; School Change.

\footnotetext{
${ }^{1}$ Pedagoga e Mestre em Ensino de Ciências e Matemáticas pela Universidade Federal do Pará (2015)
} 


\section{Introdução}

$\mathrm{O}$ ato de planejar, na visão antropológica, é inerente aos ser humano. Para essa visão, é o que o diferencia dos animais, especiando-se como sujeitos de ações e práticas. Nesse sentido, planejar é uma ação que o homem pensa e coloca em prática desde o período de hominização até a contemporaneidade, através de diferentes discursos que ganham ênfase no decorrer do tempo e da história.

Com os avanços e evolução da história, a preocupação de planejar passou a fazer parte dos diferentes campos e áreas de conhecimento de que os sujeitos se constituem. Para Moreira (1998, p. 28), “A partir do desenvolvimento comercial e industrial ocorrido no capitalismo, se iniciou a preocupação de planejar na área da economia, expandindo-se para as outras áreas de conhecimento.”. Tais preocupações adentraram também a área de educação, que passou a se constituir com organizações de planejamento de ensino a partir dos discursos que ganhavam força em cada momento da história.

Mais adiante faremos, uma breve abordagem sobre os tipos de planejamento do sistema educacional brasileiro e, em seguida, trataremos das diferentes perspectivas ou tendências pedagógico-filosóficas que abordaram visões sobre o planejamento do ensino educacional.

\section{Níveis de Planejamento}

O planejamento da educação brasileira atualmente é feito com uma organização por níveis que se inter-relacionam e são indissociáveis. Esses níveis podem ser agrupados em três: O planejamento educacional, o planejamento curricular e o planejamento de ensino.

No que se refere ao planejamento educacional, é considerado o mais amplo, geral e abrangente. Prevê a estruturação e o funcionamento da totalidade do sistema educacional. Determina as diretrizes da política nacional de educação.

O planejamento curricular posiciona-se, ante ao planejamento Educacional, com "uma tarefa multidisciplinar que tem por objeto a organização de um sistema de relações lógicas e psicológicas dentro de um ou vários campos do conhecimento, de tal modo que se favoreça ao máximo o processo ensino-aprendizagem.” (MOREIRA, 1998, p. 29).

No planejamento de ensino, é explicitado o planejamento curricular. Portanto, é no planejamento curricular que surge, em nível mais específico, o planejamento de ensino. Este é 
a tradução, em termos mais próximos e concretos, da ação que ficou configurada em nível de escola. Indica a atividade direcional, metódica e sistematizada que será empreendida pelo professor junto a seus alunos, em busca de propósitos definidos.

\section{Diferentes concepções (Tendências Pedagógico-Filosóficas) do Planejamento de Ensino}

As concepções de planejamento de ensino adentraram as escolas, no decorrer dos tempos, apresentando-se com maneiras de pensar e prescrever modos de planejar um "bom" ensino de qualidade. Entretanto, no meio escolar, quando se fala em planejamento, são comuns as opiniões e reclamações dos atores da educação em dizer que são práticas burocráticas, sinônimo de mais trabalho ou que não condizem com a prática vivida. Diante de tais discursos, mapearemos a seguir as diferentes perspectivas de planejamento de ensino que adentraram a escola nos últimos tempos, citando as perspectivas: tradicional, tecnicista, crítico-dialético (planejamento participativo), e o planejamento de ensino como estratégia de política cultural.

Para a concepção tradicional, o Planejamento de ensino é de um "roteiro" aplicado a qualquer realidade; Orienta o professor; estreita relação entre planejar e acontecer; não se preocupa em contemplar o contexto social e as necessidades individuais dos alunos. É um "guia", sempre retomado, servindo para anos e anos.

A Concepção tecnicista do Planejamento de ensino emerge no início dos anos 70. O planejamento de ensino, dentro dessa concepção, é visto como processo "sistematizado, mediante o qual se pode conferir maior eficiência as atividades educacionais para em determinado prazo alcançar o conjunto de metas estabelecidas.” (GIL, 1994, p.34).

A concepção crítico-dialético (Planejamento Participativo) surge nos anos 80 e 90, em oposição aos modelos anteriores. Acolhido pelos educadores progressistas, o saber passa a valorizar a participação, o diálogo, o poder coletivo local, a formação da consciência crítica a partir da reflexão sobre a prática transformadora.

O planejamento participativo constitui-se numa estratégia de trabalho que se caracteriza pela integração de todos os setores da atividade humano-social, num processo global para a solução de problemas comuns. Essa perspectiva adota o planejamento dialógico como estratégia de mudança da educação escolar, assumindo, como um de seus objetivos, promover maior participação e interação entre os membros de uma comunidade escolar no ambiente educacional que lhe é específico, a fim de criar soluções, ou tentativas resolutivas, para os 
problemas oriundos ou presentes no contexto do processo educativo que ocorre no interior da escola.

Nesse sentido, é importante a participação de todos e todas para a construção do planejamento escolar - e por que não dizer da vida escolar, pois nada melhor do que ter os envolvidos no processo educacional (alunos, alunas; professores e professoras; técnicos pedagógicos; pais e mães; pessoal de apoio da escola) como conhecedores e atuantes na/da realidade que os cerca, só assim passa a ter sentido a denominação a este tipo de planejamento educacional de Planejamento Dialógico.

\section{O Planejamento Dialógico como opção para a mudança escolar}

Essa perspectiva propõe que consideremos de modo bastante geral, a seguinte definição de planejamento:

O ato de planejar é sempre processo de reflexão, de tomada de decisão sobre a ação, processo de previsão de necessidades e racionalização de emprego de meios (materiais) e recursos (humanos) disponíveis, visando a concretização de objetivos, em prazos determinados e etapas definidas, a partir do resultado das avaliações. (PADILHA, 2001, p. 30).

Muito embora possamos concordar com essa definição e até afirmarmos que ela se

aplica a toda modalidade de planejamento - no sentido da importância da definição de necessidades de se planejar ações de modo reflexivo, proceder ao acompanhamento das ações a serem desenvolvidas com vistas ao atendimento de objetivos em prazos previamente definidos, e realizar avaliação dos resultados alcançados e a serem alcançados, e ainda considerarmos as vantagens de tomarmos atitudes a partir de um planejamento prévio -, não podemos negligenciar que, quando a confrontamos com determinados tipos de planejamento, a diferença salta aos olhos. Tal é o caso do planejamento educacional de tipo dialógico.

A definição apresentada é bastante geral, mas não suficiente quando consideramos o ambiente no qual ela se aplica. E, se considerarmos o ambiente escolar, ela pouco tem a nos oferecer, na medida em que se direciona a um tipo de planejamento de certo modo engessado e que não define papéis e atribuições sociais aos atores que fazem parte da realidade escolar, e muito menos o faz de modo colegiado pautado na dialogicidade entre estes mesmos atores educativos.

Resumidamente, a diferença pode ser encontrada: no modo como se planeja; quem participa ou não do processo de planejamento; de que modo se executa o planejamento; o 
envolvimento ou não da coletividade; a democratização ou não da definição; participação e execução dos ideais, ideias, desejos, objetivos e ações planejadas.

No âmbito escolar, o reconhecimento dessas diferenças é primordial, pois, assim, se pode optar pela adoção entre um tipo de planejamento e outro, e ter a clareza de que, a partir de tal escolha, irá depender em grande medida o sucesso ou o fracasso dos ideais de uma educação democrática, participativa, que toma como ponto de partida o caráter dialógico nas tomadas de decisões que têm impacto direto na qualidade do processo de ensino-aprendizagem e no processo de gestão escolar.

Além disso, a escola, ao assumir o planejamento dialógico como o tipo de planejamento educativo a ser adotado em todas as dimensões do processo educativo (desde o planejamento de aula até a definição da Proposta Pedagógica Escolar), deverá também - e isso o distingue dos demais tipos de planejamento educacional - desenvolver e incentivar o diálogo como estratégia para a resolução de problemas, o respeito à diversidade e à liberdade, seja cultural, religiosa, ética, econômica, social ou política.

\section{A imprescindível participação de todos}

Sabemos que essas necessidades apresentadas pelo planejamento educacional dialógico não estão ainda presentes na maioria de nossas escolas. $\mathrm{O}$ atendimento a elas requer, entre outras coisas, uma mudança de perspectiva a respeito do ato de educar e se educado, ou seja, requer uma conversão do olhar para a função social do ato de educar tanto da escola quanto do professor, requer também participação ativa daqueles que necessitam da escola como espaço possível de construção da transformação social.

Não podemos mais buscar justificativas paliativas para a não adoção de estratégias mais dialógicas, participativas e democráticas no contexto da escolarização e das instituições onde ocorre o fenômeno educativo. Não podemos (ou não devemos) aceitar atitudes antidemocráticas, egoístas, interesseiras, centralizadoras, etc., venham de onde vierem. O que devemos (e podemos) fazer de modo cotidiano é desenvolver atitudes e ações participativas e incentivar a imprescindível participação de todos nas decisões que nos atingem direta e indiretamente. Sem essa atitude, pouco ou nada se garante a respeito da instauração de uma gestão democrática da escola, se entendermos gestão em seu sentido educativo mais amplo. De outro modo, nada garante que haverá interesse, envolvimento, participação nas elaborações de projetos educativos e tomadas de decisões na vida da escola por parte daqueles que dão existência a ela. 


\section{O Planejamento de Ensino como Estratégia de Política Cultural}

Esta perspectiva de Planejamento de ensino é discutida por Sandra Mara Corazza a partir de teorias pós-críticas, pensando em uma Pedagogia Cultural, a partir de práticas culturais de pesquisa e ensino que centram seus esforços em ver o que está definido e como os eventos foram definidos na sociedade.

Com tal olhar aposta em mudanças na prática de ensino e na formação dos professores, lançando o desafio de uma "docência artística", o professor deixa de ser um mero executor de planejamento de "terceiros" (currículo, livros didáticos e discursos pedagógicos), e passa a experimentar, criar, inventar a própria prática em seus movimentos múltiplos.

O movimento da Pedagogia Cultural é aqui considerado uma importante prática cultural exercida por meio de análises sobre poder, linguagem, diferença e multiplicidade. É um trabalho por um planejamento de ensino que analisa o "mundo cultural".

Dessa forma, preocupa-se menos com questões metodológicas de transmissão e processos de avaliação, do que com os modos como os saberes e os produtos culturais são fabricados, divulgados e consumidos, caracteriza-se como sendo uma prática que questiona (de forma hipercrítica) os discursos culturais que moldam as experiências, as relações, os gestos e os gostos cotidianos.

Assim, propor um planejamento de ensino como estratégia de política cultural é produzir uma visão política e um espaço de lutas culturais. Com isso, essa visão não pretende desprezar os conteúdos universais, nacionais e regionais, mas realizar ajustes e rearticulações de forma que ajude a compreender de que modo o funcionamento do poder, o estabelecimento de privilégios e a constituição de determinadas subjetividades movimenta a vida de uma sociedade em uma dada direção e não de outras.

\section{Conclusão}

A compreensão da realidade escolar pelos sujeitos da educação é fundamental para que todos tomem conhecimento acerca dos problemas que acontecem na vida escolar. Assim, é fundamental que todos reconheçam a importância de sua atuação no trabalho educativo e assumam com responsabilidade o papel que lhes destina a realidade escolar através da construção coletiva do planejamento escolar como conhecedores das diferentes perspectivas do planejamento de ensino. 
Conhecendo as perspectivas de planejamento de ensino, o sujeito da sociedade contemporânea tem possibilidades de movimentar sua realidade, perscrutando sobre o que deseja concretizar no ambiente do ensino, para além do que se defronta cotidianamente no contexto escolar. Tanto uma visão crítica - que promove uma dialogicidade - como um planejamento de ensino como política cultural permitem, como condição intrínseca de sua realização, a participação não só na elaboração, mas também nas decisões a serem tomadas. Dessa forma, é preciso avançar no entendimento do que é um planejamento de ensino e desconfiar dos lugares e construções fixas de subjetividades, para centrar esforços em perceber as maneiras como definimos e como nos emocionamos com as produções do nosso tempo, e ainda como se integram tais definições e emoções ao currículo escolar e especificamente ao planejamento de ensino.

\section{Referências}

BAFFI, M. A. T. O Planejamento em Educação: revisando conceitos para mudar concepções e práticas. Petrópolis, RJ: FE/UCP, 2002.

CORAZZA, Sandra Mara. Planejamento de ensino como estratégia de política cultural. In: MOREIRA (org.) Antônio Flávio Barbosa. Currículo: questões atuais. Campinas: Papirus, 1997.

DIAS. Rosimeri de Oliveira. Formação inventiva de professores. RJ, Lamparina, 2012.

GANDIN, D. A prática do planejamento participativo. 2.ed. Petrópolis: Vozes, 1994.

GIL, Antônio Carlos. Metodologia do ensino superior. SP. Atlas, 1994. Planejamento como prática educativa. 7.ed. São Paulo: Loyola, 1994. Posição do planejamento participativo entre as ferramentas de intervenção na realidade. Currículo sem Fronteira, v.1, n. 1, jan./jun., 2001, pp. 81-95.

LIMA, L. C. Organização Escolar e democracia radical: Paulo Freire e a governação democrática da escola pública, $2^{a}$ ed. São Paulo: Cortez, 2002.

MOREIRA, M.A. Teoria do desenvolvimento cognitivo de Piaget. In: Moreira, M.A. Teorias de Aprendizagem. São Paulo: EPU, 1998.

PADILHA, R. P. Planejamento dialógico: como construir o Projeto Político-Pedagógico da Escola. São Paulo: Cortez, Instituto Paulo Freire, 2001.

VASCONCELLOS, C. dos S. Planejamento: Projeto de Ensino Aprendizagem e Projeto Político-Pedagógico, elementos pedagógicos para elaboração e realização. 15. ed. São Paulo: Libertad Editora, 2006.(cadernos pedagógicos do libertad; v.1).

Planejamento: Plano de Ensino - Aprendizagem e Projeto Político - Pedagógico. 10 ed. Libertad; São Paulo, 2002. 
VEIGA, I. P. (Org.). Projeto político-pedagógico da escola: uma construção possível. 13ª . ed. Campinas: Papirus, 2001. 